\title{
Trans IIM Special Issue on Design and Manufacturing: Guest Editorial
}

\author{
Sanak Mishra ${ }^{1}$
}

Received: 29 April 2021/Accepted: 29 April 2021/Published online: 28 May 2021

(C) The Indian Institute of Metals - IIM 2021

The idea of a "Special Issue" of the Transactions of IIM on "Design \& Manufacturing" emerged in August 2020 from consultations which Prof. Amol Gokhale, the President of IIM and Prof. B. S. Murty, the Chief Editor of Trans IIM had with me. At the suggestion of Prof. Gokhale, myself and Prof. Jyoti Mazumder, Robert H Lurie Professor of Engineering at the University of Michigan were roped in as its co-editors.

It might be mentioned that Trans IIM generally publishes research articles of high quality by authors who are primarily from academia and R\&D institutions. The approach followed for the special issue was that it would not necessarily be research-focussed, but instead it would focus on innovations in design, engineering and manufacturing process and practice. Well-known experts were invited to contribute papers. Standard review and editorial processes of Trans IIM were followed in scrutinising and selecting the papers. The reviewers were carefully chosen and invited, on the basis of their expertise and standing.

The accepted papers in the special issue are from academia, R\&D and industry, covering both scientific and technological domains. They are comprehensive and of high quality and encompass a wide range of subject fields in Metallurgy, and Materials Science \& Engineering. There is an excellent mix of papers; several reviews are the state of art while others represent new and novel results. As a whole these papers will add much value to Trans IIM, besides advancing our knowledge base.

I would like to thank the invited authors for their excellent contributions, and the invited reviewers for their timely co-operation given the tight time-frame. Although it is not a standard practice to name the reviewers, the guest editors would like to make an exception as without their co-operation the special issue could not have been finalised in the tight time frame. They are: Dr. Pradip, Mr. Manoranjan Ram, Prof. Bhanu Shankara Rao, Prof. Bankim Chandra Ray, Prof. Kalyan Kumar Ray, Dr. Sandip Ghosh Chowdhury, Dr. Santanu Kumar Ray, Prof. Dipak Mazumdar, Prof. Amit Agrawal, Prof. VS Raja and Dr. Subramanian Narayanan.

Thanks are also due to Prof. Gokhale and Prof. Murty for their valuable suggestions and keen interest.

A special mention must be made of Dr. Arup Dasgupta, the Managing Editor of Trans IIM, who was always available for consultation and provided instant support, whenever needed.

Dr. Sanak Mishra, Former President of IIM (2009-10)

May 1, 2021

Publisher's Note Springer Nature remains neutral with regard to jurisdictional claims in published maps and institutional affiliations.

Sanak Mishra

mishra.sanak@gmail.com

1 New Delhi, India 